\title{
Experimental work on the Low Reynolds Number Behaviour of 2-Hole Offset Probes
}

\author{
Ajit, Iqbal Ahmed Khan
}

\begin{abstract}
Whenever a dusty or slurry air passes through the $L$ type pitot tube its impurities struck at $90^{\circ}$ bend, resulting in the partially choking of the air flow through this device. And eventually its accuracy is decreased with the passage of time. Alternatively, such type of obstruction of the air flow can be avoided by using $S$ type pitot tube. Keeping this in mind, in the present work we had used $S$-type pitot tube of diameters ranging from $1.23 \mathrm{~mm}$ to $9.54 \mathrm{~mm}$ to test against the standard (L-type) pitot tube to control the accuracy of S-type pitot tube co-efficient. An experimental work has been carried out in a simulated wind tunnel environment. The results of the present work showed that there a slight dip over a velocity range of 3 to $14 \mathrm{~m} / \mathrm{s}$. Further, it is observed that for higher Reynolds numbers or at higher velocities of the air (more than $14 \mathrm{~m} / \mathrm{s}$ ) the co-efficient performance of $S$-pitot tube is found almost constant.

Keywords: 2-Hole Offset Probes, S-type Pitot tube coefficients;
\end{abstract} Wind tunnel test; Stack gas velocity

\section{INTRODUCTION}

A Two-hole offset probe (S-type probe) and Pitot-static probe (L-type probe) are pressure measurement instruments used to measure fluid flow velocity $[1,2]$. The working principle and objective of both probes are similar, but the geometries are different. However, two-hole offset probe has been shown to be efficient in high concentration slurry environment because obstruction does not occur during flow in the tube $[3,4,5]$. L-type probe is bent by $90^{\circ}$ between leg length and nominal length therefore obstruction occurs during the slurry flow. When particles pass through bend, they are trapped and this type of obstruction stops the fluid flow in L-type probe [6]. Manufacturing process of S-type probe is easier than L-type probe, and manufacturing cost is also less [2, 7]. Therefore, we have used S-type probe instead of L-type probe. The pitot-static probe has a coefficient close to one $( \pm 0.5 \%)$ and hence can be used without calibration while the probe coefficient of the twohole offset probe is sensitive to slight variation in geometry and hence needs calibration before use $[8,3]$. The response time of two-hole offset probe is less than that of Pitot-static probe because inner diameter of S-type probe is larger than that of L-type probe.Earlier studies reported the effect of geometries of S-type probe on flow velocity measurements [9, 10, 11]. Kang and colleagues conducted experimental and numerical studies to determine the factors that affect the accuracy of the flow rate measurement using the S-type probe [2]. They investigated effect of the Reynolds numbers, misaligned

Revised Manuscript Received on May 15, 2020.

*Correspondence Author

Ajit, M.*, Tech student, Department of Mechanical Engineering, Lingaya's Vidyapeeth, Faridabad, Haryana, India. E-mail: ajit7551@gmail.com

Iqbal Ahmed Khan, Professor \& Head, Department of Mechanical Engineering, Lingaya's Vidyapeeth, Faridabad, Haryana, India E-mail: khaniqbalahmed@yahoo.com

(C) The Authors. Published by Blue Eyes Intelligence Engineering and Sciences Publication (BEIESP). This is an open access article under the CC BY-NC-ND license (http://creativecommons.org/licenses/by-nc-nd/4.0/) installations and manufacturing quality on S-type probe coefficients by considering the flow rate measurement environment in industrial stacks. They found that deviation and uncertainty of S-type probe coefficients in the range of $3000<\operatorname{Re}<22,000$ were less than $0.3 \%$ and $1.2 \%$, respectively. Hence, as long as S-type probe was manufactured properly, the change of Reynolds numbers has no effect on probe coefficient. However, Trang and colleagues reported variation of coefficient of S-type probe on five different manufactures of S-type probe. The results of these experiments indicate that the coefficient curve of Stype probe fluctuated at small velocities around from $0.2 \%$ to $0.7 \%$. The trend of coefficient curve oscillates more strongly $( \pm 1 \%)$ at low range of Reynolds number than larger one. Most of the coefficient values for the S-type probe in this study were 0.81 or 0.82 which is smaller than suggested value of $0.84 \pm 0.01$ [10]. Williams and Dejarnette studied the effect of geometry and construction of S-type pitot tube on the accuracy of S-type probes. Fourteen different S-type pitot tube configurations were tested in the North Carolina State University subsonic wind tunnel at speeds from $4.52 \mathrm{~m} / \mathrm{s}$ to $30.48 \mathrm{~m} / \mathrm{s}$ to determine the effects of probe geometry and speed on the pitot coefficient. They found that the probe coefficient decreases slightly as the velocity increases, but this decrease is sufficiently small for the probe coefficient to be represented by an average value in this range of velocities, and its probe coefficient would change less than $5 \%$ of the accepted value of 0.85 , therefore, it is recommended for future applications [9].In the present study, S-type probe is used to determine the stack gas velocity and volumetric flow rate for stack or dusty environment (Figure 1) [1]. We evaluate the variation in coefficient of S-type pitot tube with changes in the velocity of the air in the range from $3.73 \mathrm{~m} / \mathrm{s}$ to $33.97 \mathrm{~m} / \mathrm{s}$. Here we use S-type probe of different diameters ranging from 1.23 to 9.54 to see the effect of Reynolds number on coefficients of S-type pitot tube. During the flow rate measurement with an S-type probe it was noticed that the probe coefficient showed a dip in a certain range of speeds. We further determine if this dip is real and how it varies with Reynolds number.

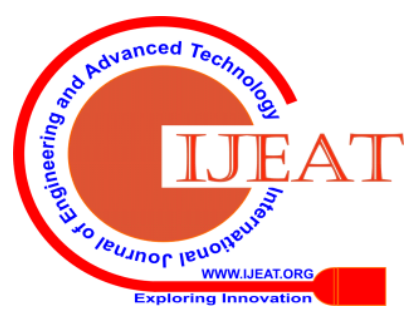




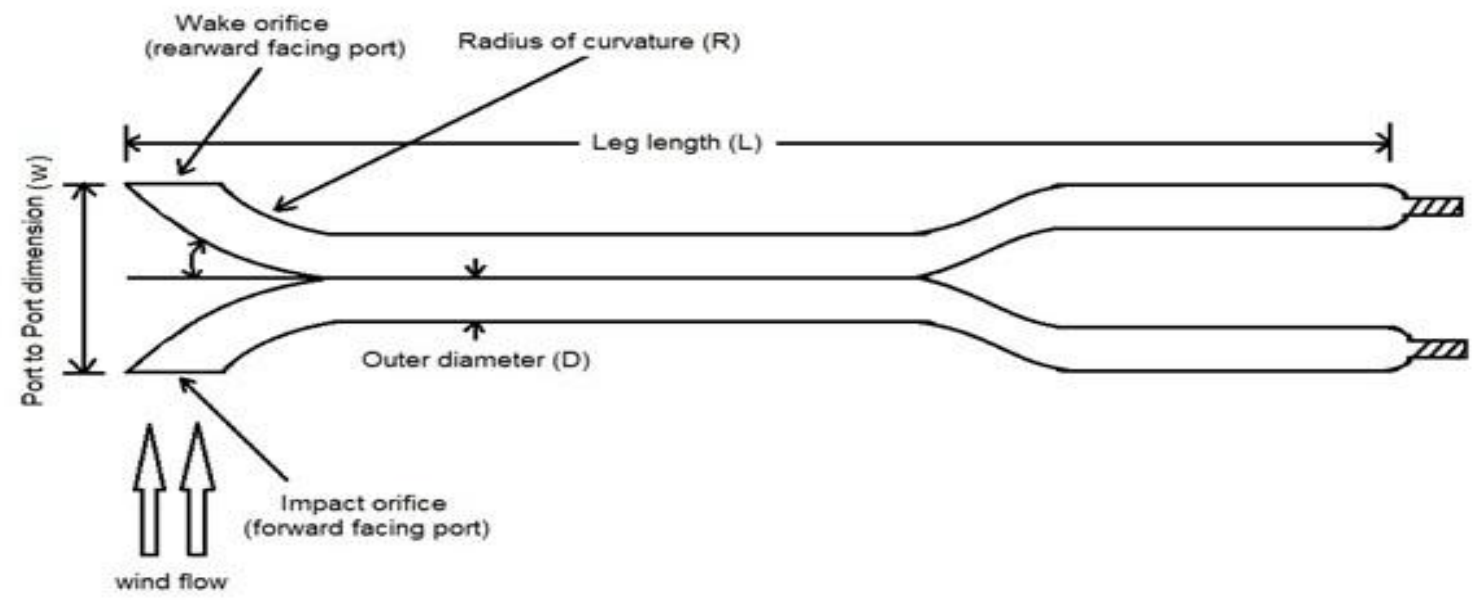

Figure 1: S-type probe and nomenclature

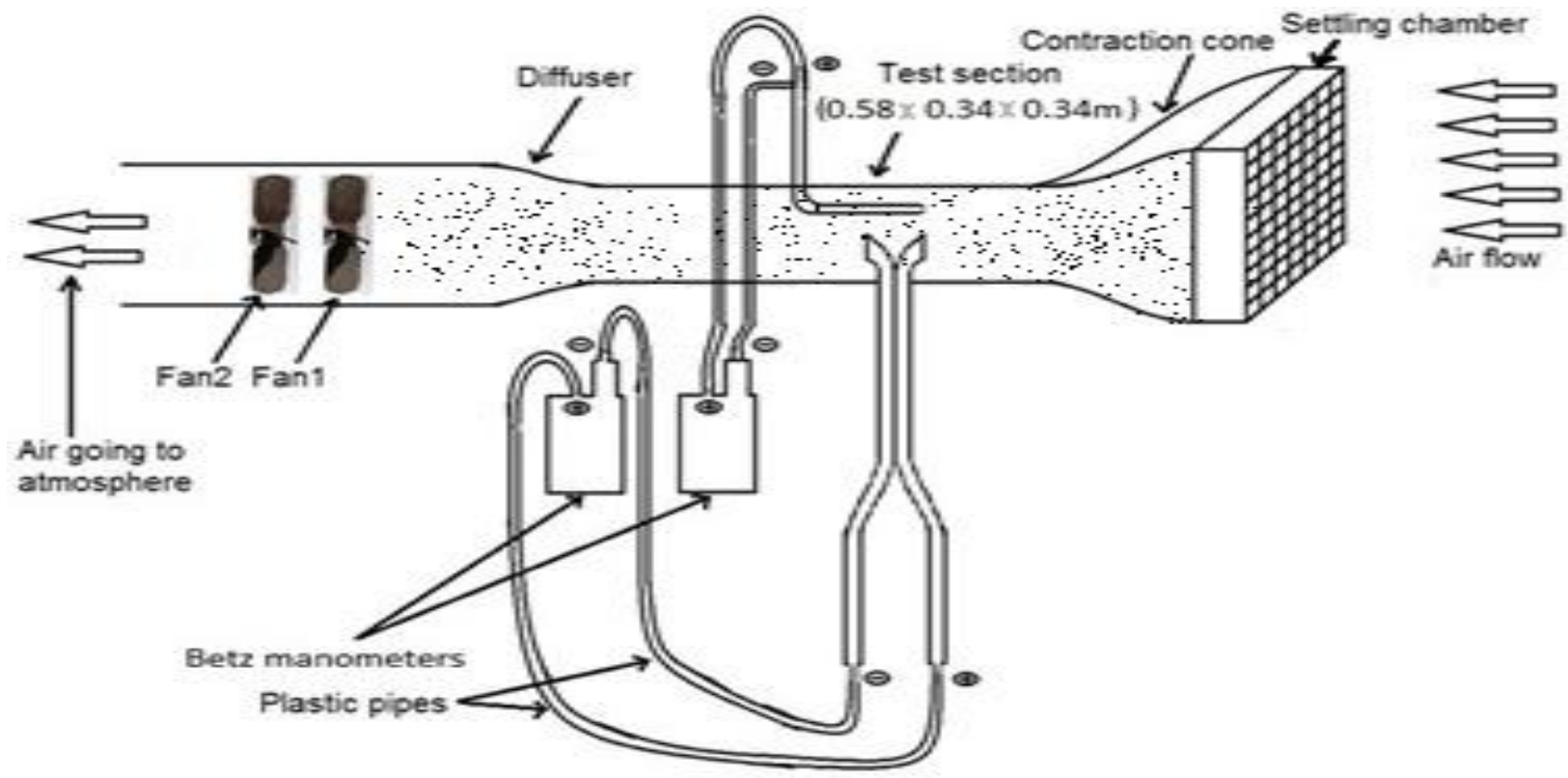

Figure 2: Systematic diagram of experimental setup

\section{METHODOLOGY}

\section{A. Experimental Setup}

The experiments are conducted inside the wind tunnel (Figure 2). First, the air flows from the drive section and then enters into the settling chamber. The function of the driver is to control the volume and the velocity of airflow. Subsequently, due to the structure of cone velocity of the air spontaneously increases which results a substantial pressure difference. The readings of pressure difference are measured by the manometer. The air having high constant velocity then enters into the test section where the model is to be tested. After that the air will flow into the diffuser and exit into the atmosphere [12].

\section{B. Physical Description Of Apparatus}

1. Both the S-type probe and L-type probe are fixed properly in the center of test section $(0.58 \mathrm{~m} \times$ $0.34 \mathrm{~m} \times 0.34 \mathrm{~m}$ ) of wind tunnel at the same downstream location as shown in Figure 2.
2. This case was taken to ensure that the probes are properly aligned with the flow to remove the yaw and pitch effects.

3. The two probes were kept sufficiently apart so that no aerodynamic interference was present.

4. Now both pitot tubes are properly connected with manometer through plastic pipes.

5. Leakage of air around the test section in wind tunnel is also checked.

\section{Procedure}

1. Fan-1 is switched on and the frequency is increased by a step of $5 \mathrm{~Hz}$, starting from zero to $50 \mathrm{~Hz}$.

2. For each frequency the reading is taken in the manometers (for the both S-type probe and L-type probe).

3. Once the fan- 1 reaches the frequency of $50 \mathrm{~Hz}$, fan-2 is switched on.

Blue Eyes Intelligence Engineering

\& Sciences Publication

(C) Copyriaht: All riahts reserved.

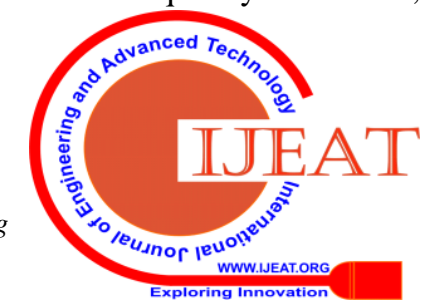


4. Now frequency of fan-2 is also increased from 0 to $50 \mathrm{~Hz}$ with a step of $5 \mathrm{~Hz}$. Similarly, for each step the manometer reading is noted down.

5. When fan-2 reaches $50 \mathrm{~Hz}$ the frequency is noted as $50+50 \mathrm{~Hz}$.

6. Now frequency of fan-2 is lowered from 50 to $0 \mathrm{~Hz}$ with step of $5 \mathrm{~Hz}$. And the reading of manometer is noted.

7. The frequency of fan-1 is reduced with step of $5 \mathrm{~Hz}$ from 50 to $0 \mathrm{~Hz}$ and noted the manometer reading.

8. Repeated this experiment for different dimensions of S-type probes.

\section{Mathematical Formulas}

S-type pitot coefficients are calibrated by comparing with corresponding coefficients of standard L-type pitot tube [13]. Manometer provides the values of $(\Delta p)_{s t d}$ and $(\Delta p)_{s-t y p e}$. Thereafter, the coefficient of S-type pitot tube $\left(C_{p s \text {-type }}\right)$ are calculated as

$$
C_{p \text { s-type }}=\sqrt{\frac{(\Delta p)_{s t d}}{(\Delta p)_{s-t y p e}}}
$$

Subsequently, the velocity is determined from the measured pressures on the fore and aft legs of the S-type probe tube from the following relations [14]

$$
v_{\text {air }}=C_{p \text { s-type }} \sqrt{\frac{2\left(p_{f}-p_{a}\right)}{\rho_{\text {air }}}}
$$

where, $\left(p_{f}-p_{a}\right)$ is S-type probe pressure difference

$p_{f}=$ pressure measure in the forward-facing port (fore) of S-type probe (pa)

$p_{a}=$ pressure measure in the rearward facing port (aft) of S-type probe (pa)

Reynolds number are calculated by following formula

$$
R e=\frac{v_{\text {air }} \times D}{\vartheta_{\text {air }}}
$$

The value of $\vartheta_{\text {air }}$ (Coefficient of viscosity) was kept at $1.8958 \times 10^{(-5)} \mathrm{Pa}-\mathrm{s}$. D is the diameter of S-type pitot tube.

Lastly,

$$
\begin{aligned}
& \text { Normalization of } \mathrm{Cp} \\
& =\frac{\text { each value of } \mathrm{Cp}}{\text { almost constant value occur of } \mathrm{Cp}}
\end{aligned}
$$

\section{RESULT AND DISCUSSIONS}

\section{A. Effect Of S-Type Probes With Different Diameters At $25^{0}$ Without Inter Tube Spacing}

An example of coefficient S-type pitot tube of scatter value for diameter 9.54 having Reynolds value $2114<\mathrm{Re}<19238$ is illustrated in Figure 3. Coefficient value shows more scatter for Reynolds number 2990 to 10059 and corresponding coefficient value ranges from 0.863 to 0.834 . Thereafter coefficient value decreases upto 0.833 where Reynolds number is 11486 and then shows nearly constant value. Therefore, coefficient value $(\mathrm{Cp})$ is normalized to 0.833 and $45.4 \%$ of coefficient values in set of data are smaller than or equal to normalized value (0.833) (Figure 3 ). We have drawn the error bar for some coefficient point in the graph. The error in coefficient value decreases when Reynolds number increase, for Reynolds number range of 250 to 4000 the error is in between $\pm 5 \%$ and $\pm 1 \%$. Also, for Reynolds number greater than 4000, error is less than $\pm \mathbf{1} \%$. After investigation we found that this type of error trend is shown in all experiments for S-type probes with different diameters at $25^{\circ}$.

Likewise, all the calculation values for other diameters are calculated and summarized in Table 1 and illustrated in Figure 4. Experiment was conducted for S-type probe with different diameter ranging from 1.23 to $9.54 \mathrm{~mm}$ and their respective dip, Reynolds value, onset of flat curve, normalizing value of probe coefficient, coefficient of S-type pitot tube, scatter in the range of Reynolds number and corresponding probe coefficient values are summarized in Table 1.

Change in the dynamics of coefficient of S-type pitot tube with Reynolds number are plotted in Figure 4. From Figure 4 , it can be seen that plot of coefficient value of different diameter of S-type probe at $25^{\circ}$ angle shows flat curve after Reynolds number 4000. Fluctuation in pressure difference increases when the diameter of S-type probe is increased. Fluctuation in pressure difference of $1.25 \mathrm{~mm}$ diameter of Stype probe is very less than that of $6.0 \mathrm{~mm}$ diameter which in turn is lesser than that of $9.54 \mathrm{~mm}$ diameter. When Port to Port dimension is small, pressure fluctuation is large because the stream is not stable and gap between ports is sufficient to generate the stream. If Port to Port dimension is larger, forward port pressure do not affect the rearward port.

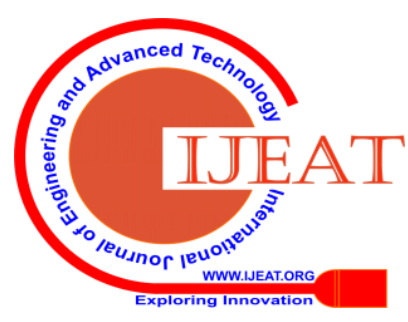


Experimental work on the Low Reynolds Number Behaviour of 2-Hole Offset Probes

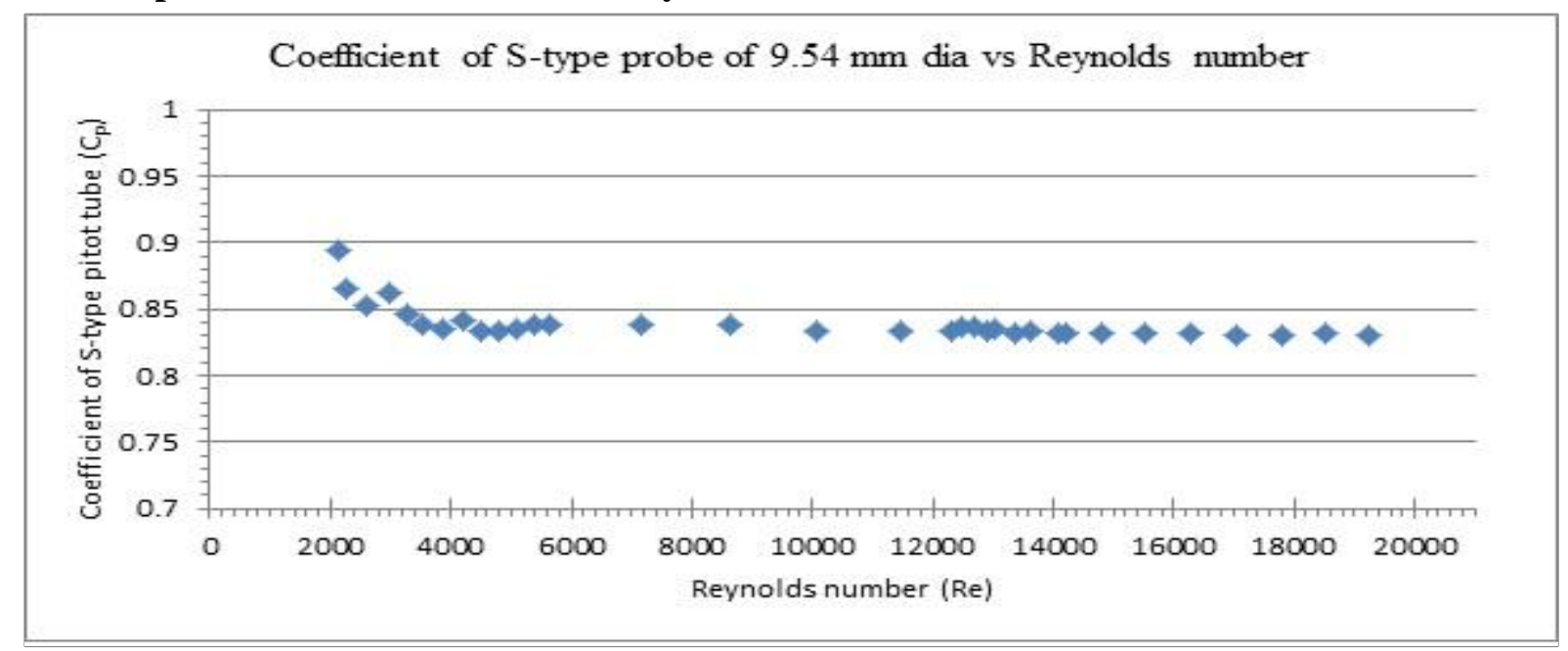

Figure 3: Reynolds number effects on the $9.54 \mathrm{~mm}$ diameter of S-type probe

Table 1: Experimental data of S-type probes with different diameters at $25^{\circ}$ without inter tube spacing

\begin{tabular}{|c|c|c|c|c|c|c|c|c|}
\hline S.No. & $\begin{array}{l}\text { Diameter } \\
\text { (D) in } \\
\text { mm } \\
\text { of S-type } \\
\text { probe }\end{array}$ & $\begin{array}{c}\text { Port to } \\
\text { Port } \\
\text { dimension } \\
\text { (w) in mm } \\
\text { (w/D) }\end{array}$ & $\begin{array}{l}\text { Dip } \\
\text { occur }\end{array}$ & $\begin{array}{c}\text { Experiment } \\
\text { was } \\
\text { conducted } \\
\text { in the } \\
\text { range of } \\
\text { Reynolds } \\
\text { number }\end{array}$ & $\begin{array}{l}\text { Scatter in the } \\
\text { range of } \\
\text { Reynolds } \\
\text { number and } \\
\text { corresponding } \\
\text { probe } \\
\text { coefficient } \\
\text { values }\end{array}$ & $\begin{array}{c}\text { Flat } \\
\text { curve } \\
\text { show } \\
\text { after } \\
\text { Reynolds } \\
\text { number }\end{array}$ & $\begin{array}{c}\text { Normalizing } \\
\text { value of } \\
\text { probe } \\
\text { coefficient }\end{array}$ & $\begin{array}{l}\text { Coefficient } \\
\text { value in } \\
\text { the set of } \\
\text { data are } \\
\text { smaller } \\
\text { and equal } \\
\text { to } \\
\text { normalized } \\
\text { value }\end{array}$ \\
\hline 1 & 9.54 & $\begin{array}{l}26.95 \\
(2.82)\end{array}$ & Not & $\begin{array}{c}2114 \text { to } \\
19238\end{array}$ & $\begin{array}{c}12990 \text { to } 10059 \\
(0.863 \text { to } \\
0.834)\end{array}$ & 11486 & 0.833 & $45.4 \%$ \\
\hline 2 & 8.0 & $\begin{array}{l}22.60 \\
(2.82)\end{array}$ & Not & $\begin{array}{c}1242 \text { to } \\
17385\end{array}$ & $\begin{array}{c}1242 \text { to } 9251 \\
(0.836 \text { to } \\
0.827)\end{array}$ & 11514 & 0.828 & $60.60 \%$ \\
\hline 3 & 6.40 & $\begin{array}{l}18.80 \\
(2.82)\end{array}$ & Yes & $\begin{array}{c}1127 \text { to } \\
13913\end{array}$ & $\begin{array}{c}1127 \text { to } 3381 \\
(0.832 \text { to } \\
0.846)\end{array}$ & 9631 & 0.853 & $84.84 \%$ \\
\hline 4 & 6.0 & $\begin{array}{l}16.95 \\
(2.82)\end{array}$ & Yes & $\begin{array}{c}1270 \text { to } \\
13010\end{array}$ & $\begin{array}{c}1270 \text { to } 4619 \\
(0.827 \text { to } \\
0.826)\end{array}$ & 5411 & 0.825 & $78.78 \%$ \\
\hline 5 & 4.0 & $\begin{array}{l}11.30 \\
(2.82)\end{array}$ & Yes & 849 to 8700 & $\begin{array}{c}849 \text { to } 3079 \\
(0.874 \text { to } \\
0.866)\end{array}$ & 5785 & 0.863 & $51.51 \%$ \\
\hline 6 & 3.0 & $8.47(2.82)$ & Not & 529 to 6539 & $\begin{array}{c}529 \text { to } 2205 \\
\text { (0.866 to } \\
0.861) \\
\end{array}$ & 4523 & 0.853 & $45.45 \%$ \\
\hline 7 & 1.25 & $3.53(2.82)$ & Not & 260 to 2692 & $\begin{array}{c}260 \text { to } 944 \\
(0.833 \text { to } \\
0.852)\end{array}$ & 1776 & 0.845 & $48.48 \%$ \\
\hline 8 & 1.23 & $3.47(2.82)$ & Not & 251 to2650 & $\begin{array}{c}251 \text { to } 1405 \\
\text { (0.866 to } \\
0.852)\end{array}$ & 1937 & 0.846 & $24.24 \%$ \\
\hline
\end{tabular}

Retrieval Number: E9669069520/2020@BEIESP
Published By:

Blue Eyes Intelligence Engineering

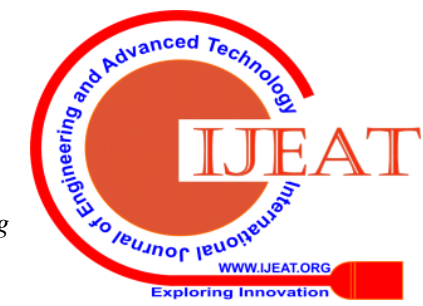




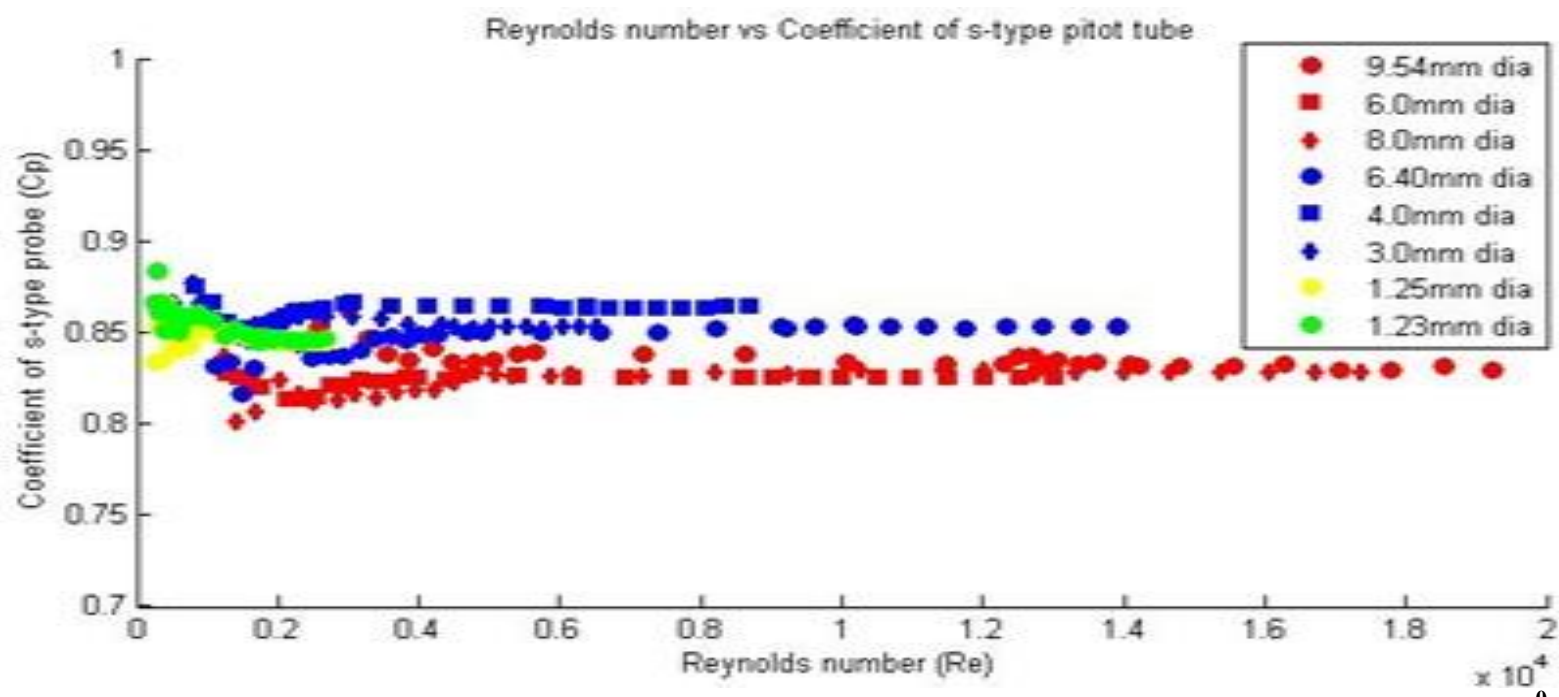

Figure 4: Combine graph of coefficient of S-type probes vs Reynolds number for different diameter of probes at $25^{0}$ angle

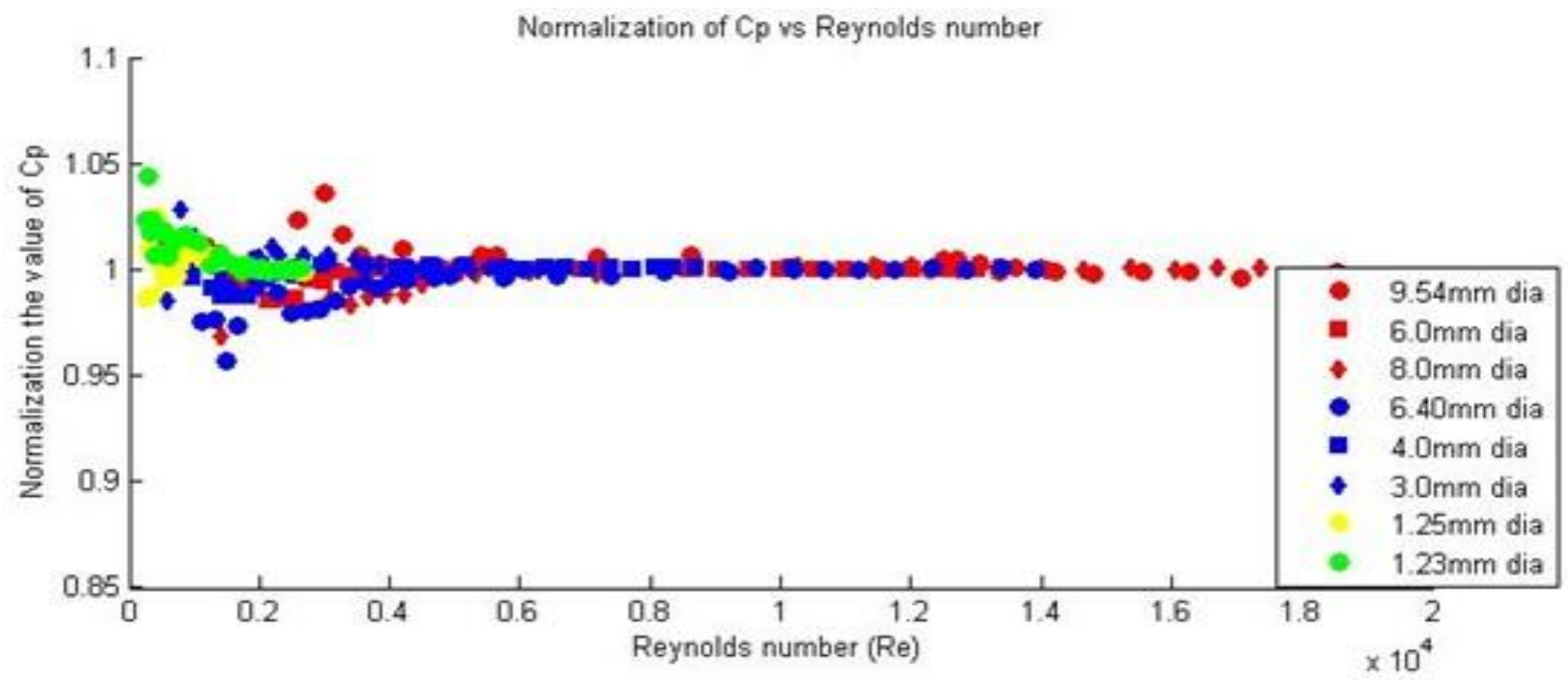

Figure 5: Normalization of coefficient of S-type probes vs Reynolds number for different diameter of probes at $25^{\circ}$ angle.

Earlier researcher reported that with increase in the velocity there is slight reduction in the probe coefficient [9]. However, here we show that probe coefficient of S-type probes shows more fluctuation in the range of Reynolds number from 250 to 4000 and shows almost constant value after that, therefore coefficient of S-type probes is normalized, after normalization we compare the result of different diameter of S-type probes [15]. Klopfenstein reported low value of probe coefficient with lowering air velocity [16]. The high fluctuation in the coefficient at low Reynolds number has been also shown by Trang and colleagues [10].

Afterwards, all normalisation values of coefficient value of S-type probes (Cp) with corresponding diameter of S-type probe are plotted in Figure 5. We found that dip only occur with three probes (like 6.40, 6.0 and $4.0 \mathrm{~mm}$ ) and there is no dip with other S-type probes at $25^{\circ}$ angle. Dip occurs in some S-type probes due to low value of Reynolds number.

\section{CONCLUSIONS AND FUTURE APPLICATIONS}

The low Reynolds numbers behaviour of 2-hole offset probes are studied by testing the S-type probes in a standard air speed system. Factors that affect the probe coefficient were also studied. On the basis of discussion following conclusions are drawn:

1. The coefficient value shows more scattered value at low range of Reynolds number than larger one.

2. It is also observed that no consistent dip occurs.

3. S-type probes showed very scattered value of probe coefficients in the range of 650 to 4000 Reynolds number (corresponding velocity $3 \mathrm{~m} / \mathrm{s}$ to $14 \mathrm{~m} / \mathrm{s}$ ) and displayed almost constant values after that. Additionally, for the Reynolds number greater than 4000 , probe coefficient is

4. Almost constant and scatter lies between $\pm 1 \%$, which corroborates with result of Kang and colleagues [2].

5. Coefficient value scatters for wide range of velocity, if diameter of S-type probe is less than 4.0 $\mathrm{mm}$. Therefore S-type probe of less than $4.0 \mathrm{~mm}$ diameter is not beneficial.

Published By:

Blue Eyes Intelligence Engineering

Retrieval Number: E9669069520/2020@BEIESP

DOI: 10.35940/ijeat.E9669.069520

Journal Website: www.ijeat.org
453 \& Sciences Publication

(C) Copyright: All rights reserved.

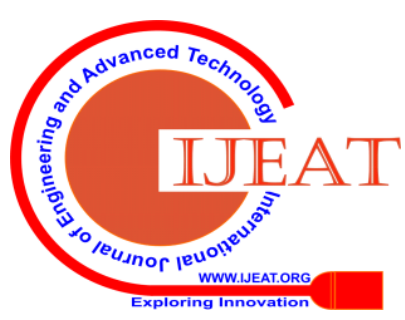




\section{Experimental work on the Low Reynolds Number Behaviour of 2-Hole Offset Probes}

Our results showed that the Two-hole offset probe (S-type probe) works efficiently even in slurry environment regardless of its diameters $(1.23 \mathrm{~mm}$ to $9.54 \mathrm{~mm})$ in measurement of air velocity.

Though the current findings of the S-type pitot tube are based on the wind tunnel. Further, S-type probe can be used in chimneys to explore the utility of it.

\section{ACKNOWLEDGEMENT}

We thank Mr. Pankaj Mahto (M.Tech., IIT Delhi) for helping in designing the experiments and for his constructive comments.

\section{REFERENCES}

1. Pitot, H. D. (1732). "Description d'une machine pour mesurer la vitesse des eaux courantes et le sillage des vaisseaux". Histoire de l'Académie Royale des Sciences, Année 1732. A Paris, de l'Imprimerie Royale, 103-106.

2. Kang Woong, Trang Nguyen Doan, Lee Hee Saeng, Choi Man Hae, Shim Jae Sig and Choi Yong Moon (2015). "Experimental and numerical investigations of the factors affecting the S-type Pitot tube coefficients." Flow Measurement and Instrumentation 44 (2015) $11-18$.

3. Vollaro RF. Guidelines for $\mathrm{S}$ type Pitot tube calibration. U.S. Environmental Protection Agency EPA-450/2-78-042b; 1978.

4. ISO. Stationary source emission-measurement of velocity and volume flow rate of gas streams in ducts, International Standard Organization 10780; 1994.

5. EPA. Determination of stack gas velocity and volumetric flow rate (type S Pitot tube), U.S. Environmental Protection Agency, Part 60 Appendix A, Method 2; 1971

6. Robinson, R. A., Butterfield, D., Curtis, D., \& Thompson, T. (2004) Problems with Pitots issues with flow measurement in stacks. International Environmental Technology (IET).

7. TUV NEL 2009, a review of flow measurement devices for use in stack emissions monitoring.

8. Nakayama, Y. (2018). Measurement of Flow Velocity and Flow Rate. Introduction to Fluid Mechanics, 215-232.

9. Williams J. C. and DeJarnette F. R. (1977). "A study on the accuracy of type-s pitot tubes." EPA-600/4-77-030.

10. Trang Nguyen Doan, Kang Woong, Shim Jae Sig, Jang Hee Soo, Park Seung Nam and Choi Yong Moon (2012). "Experimental study of the factors effect on the s type pitot tube coefficient." IMEKOWC-2012-TC9-05.

11. Nguyen, D. T., Choi, Y. M., Lee, S. H., \& Kang, W. (2019). The impact of geometric parameters of a S-type Pitot tube on the flow velocity measurements for greenhouse gas emission monitoring. Flow Measurement and Instrumentation, 67, 10-22.

12. U.S. Environmental Protection Agency, Determination of Stack Gas Velocity and Volumetric Flow Rate (Type S Pitot Tube). EPA method 2: 2000

13. ISO. Measurement of fluid flow in closed conduits - Velocity area method using Pitot static tubes. International Standard Organization 3966:2008

14. Miller, R. W. (1983). Flow measurement engineering handbook.

15. Leland, B. J., Hall, J. L., Joensen, A. W., \& Carroll, J. M. (1977). Correction of S-type pitot-static tube coefficients when used for isokinetic sampling from stationary sources. Environmental Science \& Technology, 11(7), 694-700.

16. Klopfenstein Jr, R. (1998). Air velocity and flow measurement using a Pitot tube. ISA transactions, 37(4), 257-263.

\section{AUTHORS PROFILE}

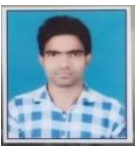

Ajit, He is currently a $2^{\text {nd }}$ year M.Tech Student in the Department of Mechanical Engineering(Production Engineering) at Lingayas Vidyapeeth, Faridabad, Haryana . He has received B.Tech in Mechanical Engineering in 2018, from Lingayas Vidyapeeth , Faridabad , Haryana

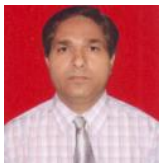

Iqbal Ahmed Khan, He received his Ph.D. in Mechanical Engineering (Ergonomics) in 2007, from Jamia Millia Islamia, New-Delhi. He did M. Tech. in (Industrial and Production Engineering) in 2000, from Aligarh
Muslim University, Aligarh, U.P., and B. E. (Mechanical Engineering) in 1995, from Jamia Millia Islamia, New-Delhi. He has more than 21 years of teaching and administrative experience of different reputed Institutes such as Galgotias University, Krishna Engineering College, Greater Noida Institute of Technology, Manav Rachna College of Engineering etc. Presently he is working as a Prof. \& Head in Department of Mechanical Engineering, Lingaya;s Vidyapeeth, Faridabad, Haryana

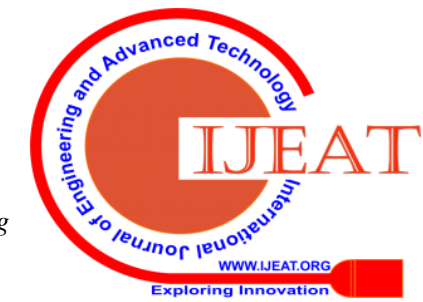

